Conclusion: Between March and July 2020, IMIDT patients, whether or not taking imeds, did not show an increased risk of reported COVID-like symptoms compared to controls. Continuing immunosuppressant drugs as long as not ill, while following the Dutch COVID rules, appears to be safe.

Disclosure of Interests: Lotte van Ouwerkerk: None declared., Andrea van der Meulen Speakers bureau: Dr. van der Meulen reports personal fees from Janssen, grants and personal fees from Takeda, personal fees from Galapogos, grants from Nestle, grants from Norgine, outside the submitted work., Grant/ research support from: Dr. van der Meulen reports personal fees from Janssen, grants and personal fees from Takeda, personal fees from Galapogos, grants from Nestle, grants from Norgine, outside the submitted work., Maarten Ninaber: None declared., Y.K. Onno Teng: None declared., Thomas Huizinga: None declared., Cornelia Allaart: None declared. DOI: 10.1136/annrheumdis-2021-eular.1387

\section{AB0668 $\quad$ THE ONSET OF RHEUMATOID ARTHRITIS AFTER COVID-19 - COINCIDENCE OR CONNECTED?}

V. Derksen ${ }^{1}$, T. Kissel ${ }^{1}$, F. Lamers-Karnebeek ${ }^{2}$, A. Van der Bijl $\left.\right|^{3}$, A. C. Venhuizen ${ }^{4}$, T. Huizinga ${ }^{1}$, R. Toes ${ }^{1}$, A. H. E. Roukens ${ }^{5}$, D. Van der Woude ${ }^{1}{ }^{1}$ Leiden University Medical Center (LUMC), Rheumatology, Leiden, Netherlands; ${ }^{2}$ Bernhoven hospital, Rheumatology, Uden, Netherlands; ${ }^{3}$ Isala hospital, Rheumatology, Zwolle, Netherlands; ${ }^{4}$ Rivierenland Hospital, Rheumatology, Tiel, Netherlands; ${ }^{5}$ Leiden University Medical Center (LUMC), Infectious Diseases, Leiden, Netherlands

Background: COVID-19, caused by severe acute respiratory syndrome coronavirus 2 (SARS-CoV-2), has been suggested to induce autoimmune phenomena. Multiple studies have reported the presence of autoantibodies in patients with COVID-19. Also the presence of anti-citrullinated protein antibodies (ACPA) and flaring of rheumatoid arthritis (RA) after COVID-19 has been described.[1, 2] Furthermore, in rheumatology clinics patients may present with polyarthritis compatible with RA shortly after SARS-CoV-2 infection. However, it is unclear how often ACPA occur after COVID-19 and whether preceding COVID-19 impacts on disease presentation of RA and phenotype of the ACPA response.

Objectives: This study aims to determine the seroprevalence of ACPA after COVID-19 and to investigate the association between preceding COVID-19 infection and disease presentation of new-onset RA, including clinical phenotype and autoantibody response.

Methods: To estimate the prevalence of ACPA after COVID-19 we measured ACPA IgG in samples from 61 patients visiting the specialized post-COVID outpatient clinic of the LUMC 5 weeks after hospitalization, using routine tests or in-house ELISA. Furthermore, we identified 5 patients presenting with polyarthritis compatible with RA after SARS-CoV-2 infection. To study the impact of COVID-19 on disease presentation, we examined clinical phenotype, autoantibody isotype positivity and ACPA IgG variable domain (V-domain) glycosylation of these patients and compared these features to regular RA patients. Autoantibody isotypes, including rheumatoid factor (RF) $\lg M / \lg A$, anti-CCP2 $\lg$ G/ $\lg M /$ $\operatorname{IgA}$ and anti-carbamylated protein antibodies (anti-CarP) IgG were measured using in-house ELISA's. The percentage of V-domain glycosylation of purified ACPA IgG was measured with UHPLC

Results: None of the 61 post-COVID patients tested positive for ACPA 5 weeks after hospitalization, except two patients previously diagnosed with ACPA-positive RA. Thus, we could not observe an increase in ACPA-positivity shortly after COVID-19. Of the 5 patients who developed polyarthritis compatible with RA after SARS-CoV-2 infection, the average age was 63.6 years and 2/5 were female. 4/5 patients had been hospitalized due to severe COVID-19. On average, joint complaints started 6.6 weeks after infection, although two patients reported symptoms before infection. 4/5 patients fulfilled the ACR 2010 criteria for RA. Three patients (patient $1,4,5$ ) were phenotypically very similar to regular new-onset RA patients. Patient 3 had a history of seronegative RA and had been in DMARD-free remission for 5 years. She flared 6 weeks after SARS-CoV-2 infection. Patient 2 had a remarkably different presentation. He was admitted with a suspected septic polyarthritis or pneumonia with reactive polyarthritis 6 weeks after COVID-19. ACPA level was low positive. The patient died unexpectedly after two days and autopsy revealed dilating myocarditis of unclear underlying cause. No causative pathogen could be identified.

Previous studies have shown that RA-patients are most often either seronegative or triple-positive for RF, ACPA and anti-CarP antibodies. Autoantibody measurements on sera of the post-COVID polyarthritis patients revealed a similar pattern (Figure $1 \mathrm{~A}$ ) with two patients being completely seronegative, and three patients positive for a range of autoantibodies. In all post-COVID samples, the percentage of ACPA IgG V-domain glycosylation was significantly increased compared to total IgG (Figure 1B), similar as in regular RA.

Conclusion: In conclusion, we found that the seroprevalence of ACPA is not increased post-COVID and that most patients presenting with polyarthritis after COVID-19 resemble regular RA patients, both regarding clinical phenotype and autoantibody characteristics. Although sample size and follow-up was limited, it appears that RA post-COVID may be coincidence rather than connected.

\section{REFERENCES:}

[1] Vlachoyiannopoulos et al. Ann Rheum Dis, 2020

[2] Perrot et al. The Lancet Rheumatology, 2020.
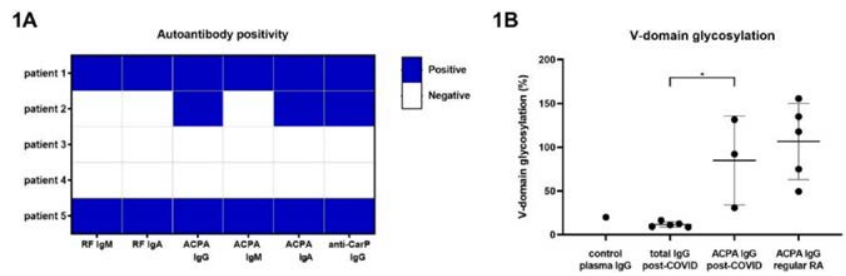

Disclosure of Interests: None declared.

DOI: 10.1136/annrheumdis-2021-eular.1398

\section{$\mathrm{AB0669}$}

DEPRESSION AND ANXIETY MIGHT NOT BE INCREASED DURING COVID-19 PANDEMIC IN PATIENTS WITH AXIAL SPONDYLOARTHRITIS

E. Erpek ${ }^{1}$, D. Solmaz ${ }^{1}$, D. Bayraktar ${ }^{2}$, G. Duran ${ }^{3}$, G. Kabadayi ${ }^{1}$, E. Durak Ediboglu$^{1}$, E. Otman Akat ${ }^{1}$, G. Alp ${ }^{1}$, H. Cinakli ${ }^{1}$, İ. Kurut Aysin ${ }^{1}$, S. Gucenmez ${ }^{1}$, O. Bayindir ${ }^{1}$, M. Ozmen ${ }^{1}$, S. Akar ${ }^{1} .{ }^{1}$ Izmir Katip Celebi University Faculty of Medicine, Rheumatology, Izmir, Turkey; ${ }^{2}$ Izmir Katip Celebi University Faculty of Health Sciences, Department of Physiotherapy and Rehabilitation, Izmir, Turkey; ${ }^{3}$ Dokuz Eylul University, Institute of Health Sciences, Department of Physiotherapy and Rehabilitation, Izmir, Turkey

Background: Anxiety and depression are most common psychiatric disorders in chronic inflammatory rheumatic condition as well as axial spondyloarthritis (axSpA) (1). The prevalence of depression has been reported as $11-64 \%$ depending on the criteria used. Also self-reported depression and anxiety were found to be associated with disease activity and function in $\operatorname{axSpA}(1,2)$. It is observed that mental health is affected among healthy subjects during the COVID-19 pandemic, but this condition has not been systematically reviewed in axSpA patients.

Objectives: We aimed to compare frequency of self-reported depression and anxiety before and during the Covid-19 pandemic in patients with axSpA.

Methods: Seventy-six axSpA patients who were evaluated for the presence of depression and anxiety by using Hospital Anxiety and Depression scale (HADs) before pandemic were included in this study. All participants were classified according to the ASAS axSpA classification criteria. Patients were contacted by phone to participate and complete the HADS questionnaire. Demographic and disease related characteristics including BASDAI, BASFI and Patient Acceptable Symptom State (PASS) were recorded during interview. The HADs cut off value was taken as $>7$ in both groups to define the presence of anxiety or depression. Before and during pandemic period anxiety and depression scores were statistically compared.

Results: The demographic and disease related characteristics of axSpA patients with and without anxiety/depression were summarized in Table 1. The frequency of anxiety (43.4\% vs \%43.4; $p>0.05)$ and depression ( $46.1 \%$ vs $44.7 \%$; $p>0.05)$ were found to be similar before and during pandemic period. Patients with anxiety (HADs >7) and depression (HADs>7) had higher BASDAI and BASFI scores and much less PASS positivity (Table 1). Although the frequency of depression was similar between before and during the pandemic period, symptom severity in depression was slightly increased during the pandemic (Figure 1)

Table 1. Patients' demographics and characteristics according to the presence of anxiety and depression

\begin{tabular}{|c|c|c|c|c|c|c|}
\hline Variables & $\begin{array}{c}\text { Presence of } \\
\text { depression } \\
\text { n:35 }\end{array}$ & $\begin{array}{c}\text { Absence of } \\
\text { depression } \\
n: 41\end{array}$ & $P$ & $\begin{array}{l}\text { Presence of } \\
\text { anxiety } n: 33\end{array}$ & $\begin{array}{l}\text { Absence of } \\
\text { anxiety n:43 }\end{array}$ & $P$ \\
\hline $\begin{array}{l}\text { Age (years) mean } \\
\quad \pm \mathrm{SD}\end{array}$ & $41.8 \pm 11.2$ & $44.1 \pm 9.3$ & $>0.05$ & $42.0 \pm 10.9$ & $43.6 \pm 10.0$ & $>0.05$ \\
\hline Male $n(\%)$ & $21(60.0)$ & $26(63.4)$ & $>0.05$ & $18(54.5)$ & $29(67.4)$ & $>0.05$ \\
\hline $\begin{array}{l}\text { Education time (years) } \\
\text { mean } \pm \mathrm{SD}\end{array}$ & $9.6 \pm 4.8$ & $11.0 \pm 4.2$ & $>0.05$ & $9.7 \pm 5.0$ & $10.6 \pm 4.1$ & $>0.05$ \\
\hline Current smoker $\mathrm{n}(\%)$ & $18(51.4)$ & $15(36.6)$ & $>0.05$ & $15(45.5)$ & 18(41.9) & $>0.05$ \\
\hline $\begin{array}{l}\text { Alcohol consumption } \\
\mathrm{n}(\%)\end{array}$ & 12(34.3) & 12(29.3) & $>0.05$ & 10(30.3) & $14(32.6)$ & $>0.05$ \\
\hline $\begin{array}{l}\text { Current BMI kg/m² } \\
\text { mean } \pm \mathrm{SD}\end{array}$ & $26.0 \pm 4.8$ & $26.8 \pm 4.5$ & $>0.05$ & $26.4 \pm 5.0$ & $26.5 \pm 4.3$ & $>0.05$ \\
\hline $\begin{array}{l}\text { Sleep time (hours) } \\
\text { mean } \pm \text { SD }\end{array}$ & $7.6 \pm 1.7$ & $7.6 \pm 1.3$ & $>0.05$ & $7.5 \pm 1.6$ & $7.7 \pm 1.4$ & $>0.05$ \\
\hline $\begin{array}{l}\text { Current BASDAI } \\
\text { mean } \pm \text { SD }\end{array}$ & $2.5 \pm 1.6$ & $1.4 \pm 1.6$ & $<0.05$ & $2.7 \pm 1.8$ & $1.3 \pm 1.3$ & $<0.001$ \\
\hline $\begin{array}{l}\text { Current BASFI mean } \\
\quad \pm \text { SD }\end{array}$ & $2.4 \pm 2.1$ & $1.1 \pm 1.3$ & $<0.05$ & $2.4 \pm 2.0$ & $1.2 \pm 1.4$ & $<0.05$ \\
\hline PASS positivity $n(\%)$ & $16(45.7)$ & $29(70.7)$ & $<0.05$ & $14(42.4)$ & $31(72.1)$ & $<0.05$ \\
\hline
\end{tabular}


Current depression and anxiety scores were correlated with disease activity (HADs Depression vs BASDAI r:0.530, p<0.001; HADs Anxiety vs BASDAI $r: 0.500, p<0.001$ ) and function (HADs-Depression vs BASFI r:0.519, p<0.001; HADs-Anxiety vs BASFI $\mathrm{r}: 0.391, \mathrm{p}<0.001)$. These relationships were also observed in the pre-pandemic period (HADs-Depression vs BASFI r:0.326, $\mathrm{p}<0.05$; HADs-Anxiety vs BASDAI r:0.342, $\mathrm{p}<0.05$ )

Conclusion: Depression and anxiety symptoms seems to be comparable before and after the COVID-19 pandemic. Regardless of this period, the presence of both depression and anxiety are associated with disease activity, function and less patient acceptable symptom state.

REFERENCES

[1] Zhao S, Thong D, Miller N, et al. The prevalence of depression in axial spondyloarthritis and its association with disease activity: a systematic review and meta-analysis. Arthritis Res Ther. 2018;20:140.

[2] Barışan E, Bayır D, Solmaz D. Aksiyel spondiloartrit hastalarında anksiyete düzeyinin çeşitli ölçeklerle değerlendirilmesi ve anksiyete ile ilişkili faktörler. Dokuz Eylül Üniversitesi Tıp Fakültesi Dergisi. 2019; 129-137.

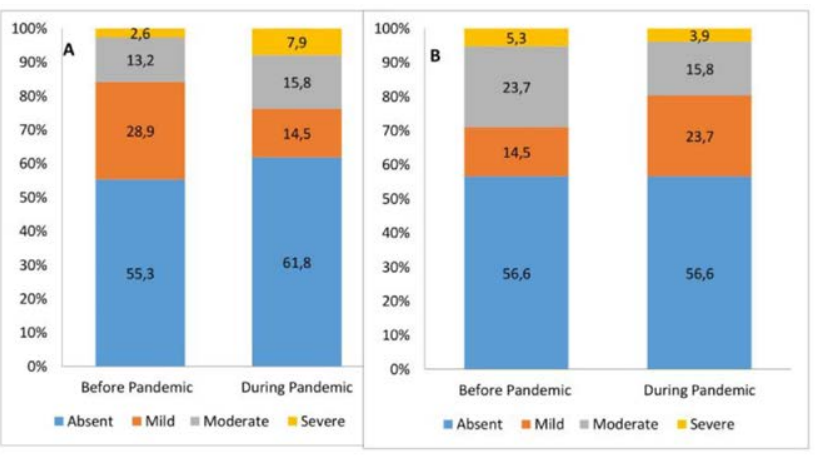

Figure: Severity of depression and anxiety in AxSpA before and during COVID-19 pandemic

Figure 1.

Disclosure of Interests: None declared

DOI: 10.1136/annrheumdis-2021-eular.1422

\section{AB0670 PATIENTS WITH ANCA-ASSOCIATED SYSTEMIC VASCULITIS, RECEIVING ANTI-B CELL THERAPY WITH} RITUXIMAB

T. Beketova ${ }^{1}$, V. Babak ${ }^{1}$, M. Suprun ${ }^{1} .{ }^{1}$ V.A. Nasonova Research Institute of Rheumatology, Moscow, Russian Federation

Background: Currently, the issues of the effect of anti-B cell therapy on the risk of severe course of COVID-19 in patients (pts) with ANCA-associated vasculitis (AAV) has not been completely studied.

Objectives: We present an analysis of the COVID-19 incidence and outcomes in 126 AAV pts treated with rituximab (RTX) from one rheumatology center registry.

Methods: Data were collected with telephone/online surveying between 11-15th November 2020 from all 126 AAV pts (58- granulomatosis with polyangiitis, GPA; 38- microscopic polyangiitis, MPA;22- eosinophilic granulomatosis with polyangiitis, EGPA (54\% ANCA-negative); and 8- uncertain AAV). Pts age was 51 (20-81) $\mathrm{yr}, 62 \%$ women. Due to AAV activity or risk of relapse, during the pandemic RTX was prescribed in $48 \%$ pts.

Results: The incidence of COVID-19 in AAV pts was 3.5\% during the first 3 months of the pandemic, the course was uneventful, and all pts recovered. Since September 2020 a 4-fold increase in the incidence alongside with more severe course of COVID-19 were reported. After 8 months of the pandemic, COVID-19 was diagnosed in 21 (16.6\%) pts with median age $55 \mathrm{yr}, 57 \%$ women. COVID-19 incidence was lower in GPA (15.5\%) vs MPA $(21.1 \%)$ or EGPA $(27.7 \%)$. The mortality rate was $14.3 \%$ (2- MPA, 1- GPA). When analyzing the 5 -year survival rate of AAV pts treated with RTX, prognosis worsening was noted; in 2020 there were 3 deaths due to COVID-19, in the previous 5 years- only 2 deaths.

Conclusion: Taking into account the fact the mechanisms of AAV and severe COVID-19 are largely synergistic (Table 1), primarily in the context of obstructive thromboinflammation as manifestation of acute inflammatory syndrome in COVID-19 [1], AAV can potentially contribute to the severe course of COVID-19. Anti-CD20 therapy seems to have a protective effect against severe COVID-19 [2], which, however, can be insufficient in AAV pts with active disease and multiple organ damage. Further analysis of COVID-19 cases in pts with AAV and other rheumatic diseases is exceptionally important.
Table 1. Comparison of AAV and severe COVID-19

\begin{tabular}{|c|c|c|}
\hline Parameter & AAV & Severe COVID-19 \\
\hline Lung damage & $\begin{array}{c}\text { High frequency of lung } \\
\text { damage }\end{array}$ & Possibly destructive lung damage \\
\hline $\begin{array}{l}\text { Damage to other } \\
\text { organs }\end{array}$ & $\begin{array}{l}\text { Typically affects the upper } \\
\text { and lower airways and } \\
\text { kidneys; Other organs can } \\
\text { be involved }\end{array}$ & Possible extrapulmonary localization \\
\hline $\begin{array}{l}\text { Vascular } \\
\quad \text { involvement }\end{array}$ & $\begin{array}{l}\text { Systemic necrotizing } \\
\text { vasculitis of small vessels; } \\
\text { In the active phase, } \\
\text { hypercoagulation }\end{array}$ & $\begin{array}{l}\text { Obstructive thromboinflammation of the } \\
\text { microcirculation of lungs and extrapul- } \\
\text { monary vessels; Increased incidence of } \\
\text { Kawasaki syndrome during the pandemic }\end{array}$ \\
\hline Inflammation & High or very high & Very high \\
\hline Autoantibodies & ANCA pathogenetic role & $\begin{array}{c}\text { Dominant extrafollicular B cell responses; } \\
\text { Correlation between SARS-CoV-2 } \\
\text { antibody titer and severity of COVID-19; } \\
\text { High titers of IFN- } \alpha 2 / \omega \text { autoantibodies }\end{array}$ \\
\hline Neutrophil & $\begin{array}{l}\text { Neutrophils are the most } \\
\text { important effector cells in } \\
\text { the pathogenesis }\end{array}$ & $\begin{array}{l}\text { Changes in the morphology of neutrophils } \\
\text { were noted; Netosis, the release of } \\
\text { proteases from neutrophils promote the } \\
\text { complement system activation, hyper- } \\
\text { coagulation, endotheliitis, production of } \\
\text { pro-inflammatory cytokines; An increase } \\
\text { of neutrophils in the blood and broncho- } \\
\text { alveolar lavage fluid were noted }\end{array}$ \\
\hline Complement & $\begin{array}{c}\text { Complement is crucial in the } \\
\text { pathogenesis; C5a recep- } \\
\text { tor antagonist Avacopan } \\
\text { efficacy }\end{array}$ & $\begin{array}{c}\text { Activation of alternative/lectin complement } \\
\text { pathways; } \mathrm{C} 5 \text { antagonist Eculizumab has } \\
\text { been reported to be effective }\end{array}$ \\
\hline Treatment & $\begin{array}{l}\text { Immunosuppressants; } \\
\text { In the active phase, } \\
\text { anticoagulants }\end{array}$ & $\begin{array}{l}\text { Anticoagulants; Glucocorticoids, pro-in- } \\
\text { flammatory cytokine antagonists, JAK } \\
\text { inhibitors, cyclosporine }\end{array}$ \\
\hline Prognosis & Serious & High mortality rate \\
\hline
\end{tabular}

\section{REFERENCES:}

[1] Ciceri F, et al. Microvascular COVID-19 lung vessels obstructive thromboinflammatory syndrome (MicroCLOTS): an atypical acute respiratory distress syndrome working hypothesis. Crit Care Resusc. 2020;22(2):95-7

[2] Montero-Escribano P, et al. Anti-CD20 and COVID-19 in multiple sclerosis and related disorders: A case series of 60 patients from Madrid, Spain. Mult Scler Relat Disord. 2020;42:102185

Disclosure of Interests: None declared

DOI: 10.1136/annrheumdis-2021-eular.1953

\section{AB0671 NO EVIDENCE OF SARS-COV-2 IN THE KNEE JOINT: A CADAVER STUDY}

M. Grassi ${ }^{1}$, V. Giorgi ${ }^{2}$, M. Nebuloni ${ }^{3}$, P. Zerbi ${ }^{3}$, M. R. Gismondo ${ }^{4}$, F. Salaffi $^{5}$, P. Sarzi-Puttini ${ }^{2}$, S. G. Rimoldi ${ }^{4}$, A. Manzotti ${ }^{1} .{ }^{1}$ ASST-Fatebenefratelli L. Sacco University Hospital, Orthopaedic and Traumatology Unit, Milan, Italy; ${ }^{2}$ ASST Fatebenefratelli L.Sacco University Hospital, Rheumatology Unit, Milan, Italy; ${ }^{3}$ ASST-FBF Sacco, University of Milan, Pathology Unit, Department of Biomedical and Clinical Sciences, Milan, Italy; ${ }^{4}$ ASST-Fatebenefratelli L. Sacco University Hospital, Microbiology Unit, Milan, Italy; ${ }^{5}$ Università Politecnica delle Marche, Rheumatology Department, Jesi, Italy

Background: Despite the considerable research efforts being made to learn more about COVID-19, little is known about the presence of SARS-CoV-2 genetic material in biological fluids other than respiratory droplets, blood, and feces ${ }^{1,2}$. In particular, little is known about the presence of SARS-CoV-2 in the joints either post mortem ${ }^{3}$ or in vivo ${ }^{4}$. To the best of our knowledge, only Lopéz-Gonzalez et al. ${ }^{5}$ have published a description of acute arthritides occurring during hospitalisation due to COVID-19, and they did not find any SARS-CoV-2 genetic material in the patients' synovial fluid samples.

Objectives: The aim of this post mortem study was to assess the presence of SARS-CoV-2 RNA in the knee synovial fluid, synovial tissue, and bone tissue of COVID-19 patients in order to discover whether the joint is a possible route of transmission during orthopaedic surgical procedures, and clarify the possible role of SARS-CoV-2 as a directly arthritogenic virus.

Methods: Post mortem synovial fluid, synovial tissue and bone tissue samples were collected from the knees of five patients who died of COVID-19 in our hos pital between September and October 2020, and analysed for the presence of SARS-CoV-2 using a commercial real-time polymerase chain reaction (RT-PCR) panel. Quantitative RT-PCR was used to test post mortem nasopharyngeal swabs of all of the patients.

Results: No SARS-CoV-2 RNA was detected in any of the knee samples, despite the positivity of the throat swab.

Conclusion: Our findings indicate that SARS-CoV-2 was not detected in knee synovial fluid, synovial membrane or bone. Therefore, our results suggest that all 